\title{
Journal of Physics and Its Applications
}

Journal homepage : https://ejournal2.undip.ac.id/index.php/jpa/index

\section{Identification of low resistivity layers in the "N" geothermal field using 2D magnetotelluric inversion modeling}

\author{
Nabil $^{1}$, Udi Harmoko ${ }^{2}$, Tony Yulianto ${ }^{2}$, and Irvan Ramadhan ${ }^{3}$ \\ ${ }^{1}$ Physics Undergraduate Study Program, Department of Physics, Diponegoro University, Semarang, Indonesia \\ ${ }^{2}$ Department of Physics, Diponegoro University, Semarang, Indonesia, udiharmoko@lecturer.undip.ac.id \\ ${ }^{3}$ Supreme Energy, Jakarta, Indonesia, Semarang, Indonesia
}

\section{A R T I C LE IN F O}

\section{Article history:}

Received : 9 April 2020

Accepted : 11 May 2020

Available online : 10 June 2020

Keywords:

Geothermal

Cap rock

Magnetotelluric

2D inversion

Time-series

Low resistivity

\begin{abstract}
A B S T R A C T
Magnetotelluric survey in the "N" geothermal field was carried out to map the distribution of resistivity value around the " $\mathrm{N}$ " geothermal field. The low resistivity value $(2-10 \mathrm{ohm} . \mathrm{m})$ which overlying the higher resistivity area beneath, usually represents geothermal system cap rocks. This study began with time-series data robust process processingto generate apparent resistivity and phase data from each MT station. 2D inversion model was constructed by using processed MT EDI Files. The final result of this study is a 2D MT model representing the lateral and vertical distribution of geothermal clay cap. Based on this study, cap rock layer was identified by low resistivity distribution (2 $\Omega . \mathrm{m}-10 \Omega . \mathrm{m})$, the medium resistivity layer (11 $\Omega . \mathrm{m}-70 \Omega . \mathrm{m})$ was identified as the transition zone, while high resistivity value (more than $70 \Omega . \mathrm{m}$ ) represented geothermal reservoir. The existence of a geothermal reservoir around " $\mathrm{N}$ " geothermal field was also supported by the occurrence of several manifestations across the area.
\end{abstract}

\section{Introduction}

The development of technology throughout the world causes the demand for energy continues to increase. Currently, fossil energy reserves as the main energy resources in the world keep depleting. Therefore, alternative energy sources are needed to replace the role of fossil energy sources, one of them is geothermal energy.

To extract the geothermal resource, a comprehensive geoscience study consisting of geology, geophysics, and geochemistry was carried out to find potential geothermal fields and to determine the location of exploration drilling wells. The existence of geothermal fluid which has high temperature and high salinity cause resistivity of the rocks as the best geophysical parameter for geothermal exploration [1]. Magnetotelluric (MT) is one of the passive geophysical methods which measures the resistivity of the rocks [2].

Magnetotelluric methods measurements involved electric field fluctuations and natural magnetic fields which were perpendicular to the surface of the earth from a depth of several meters to hundreds of kilometers [3]. Parameters measured in the MT method were natural electromagnetic signals included the earth's magnetic field ( $\mathrm{Hx}, \mathrm{Hy}$, and $\mathrm{Hz}$ ) and the earth's electric field (Ex and Ey) resulting in resistivity and phase as the parameters that needed to be analyzed [4].

The target of geothermal exploration for convective hydrothermal resources is usually a region composed of faults and fractures filled with thermal fluids and hydrothermal alteration products The low-resistivity zone produced by the brines and clays capping a geothermal system provided a feature that should be easily detectable by electromagnetic (EM) methods [5]. An important stage of MT interpretation was the elevation map of the base of the conductive (BOC) smectite clay zone corresponding to the top of reservoir (TOR) to determine the drilling point. Areas with low resistivity valuesidentified as cap rock are usually located above the reservoir zone [6]. the base of conductive (BOC) layer (low resistivity value) was collated to construct a BOC map. The trend and thickness of the conductive layer were useful to predict reservoir doming feature, and together with the resistive core, could be used to "draw" the reservoir geometry. These features of low resistivity layer and resistive core could delineate the potential productive area [7].

The cap rock acted as a reservoir cover to prevent the geothermal fluid leak from the reservoir. Cap rock was impermeable or resistant to fluid pressure and it had a low resistivity value or referred to as a conductive layer [8]. Identification of the low resistivity layer at the "N" geothermal field was the main topic of this study because it was one of the important parts of geothermal exploration.

\section{Methodology}

The data used in this study were secondary data on magnetotelluric acquisition in the " $\mathrm{N}$ " geothermal field in the form of time-domain data equipped with 
remote reference data and transverse function data. Time-series data were obtained with the Metronix ADU-07e which calculated two orthogonal components of the electric field (Ex and Ey) and three magnetic field components $(\mathrm{Hx}, \mathrm{Hy}, \mathrm{Hz})$. At each station, bandwidth range starting from $64 \mathrm{~Hz}$ up to $64 \mathrm{KHz}$, data with a bandwidth smaller than 64 $\mathrm{Hz}$ was obtained by filtering on a $64 \mathrm{~Hz}$ bandwidth to get deeper depth.

This research used some software used for data processing, data analysis, and 2D inversion modeling. The software used in this research were Mapros and Geotools. Mapros was used to perform several timeseries data processing where the format *ats were needed, including eliminating noise by adjusting the value of FFT Length, eliminating data spikes manually, and changing magnetotelluric data in the time domain to a frequency domain with fourier transforms to produce smoother transverse function curves [9]. From this software, a transverse function curve was obtained. Geotools software was used to create profiles, cross power selection processes, and to do 2D inversion modeling.

The total measurement station on the "N" geothermal field was 163 stations stretching from north to south and passing through manifestations in the form of fumaroles shown in Fig.1.

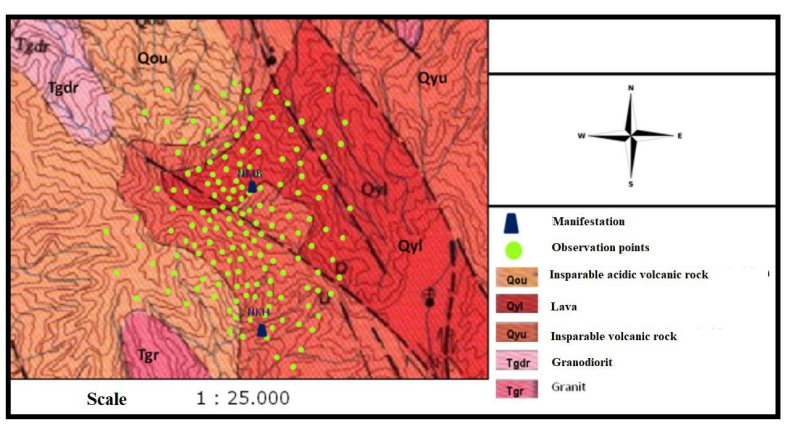

Fig.1: Survey design and geological map[10]

To reduce the static effect on data, the static shift correction process in this study was carried out by spatial filtering method and TDEM on certain data. Spatial filteringmethod assumed that regional effects that presented actual subsurface conditions would emerge after averaging. This method was done by selecting the data to be used as a corrector and as data that must be corrected.

The last process was 2D inversion modeling by adjusting inversion parameters such as mode type (TE-TM), frequency range to be used in modeling, noise floor, and data error. In this study, the parameters used were the default model parameters from Geotools and TE-TM mode was used to obtain results in a wider and more detailed resistivity range. The number of iterations also determined the quality of the model, the number of iterations used in this study was 50. All parameters were adjusted to obtain inversion results with a root mean square (RMS) value of less than $5 \%$.

\section{Results and Discussions}

The transverse function curve contained apparent resistivity and phase information that varied with the frequency of each measurement point. Sounding curves usually had a static shift effect, To eliminate the effect of the static effect on the curve, a static shift correction process was needed which could be carried out by several methods. The static shift correction methods used in this study were the spatial filtering method and TDEM. According to [11] TDEM, data was applied because it was not affected by local conductivity anomalies near the surface, and spatial filteringwas applied by assuming regional effects that presented the actual subsurface conditions that would emerge after averaging. TDEM data only covered some data and the rest was done by spatial filtering methods. In Fig 2. and Fig 3. Show the MT curve that had been done static shift correction with TDEM and spatial filtering method.

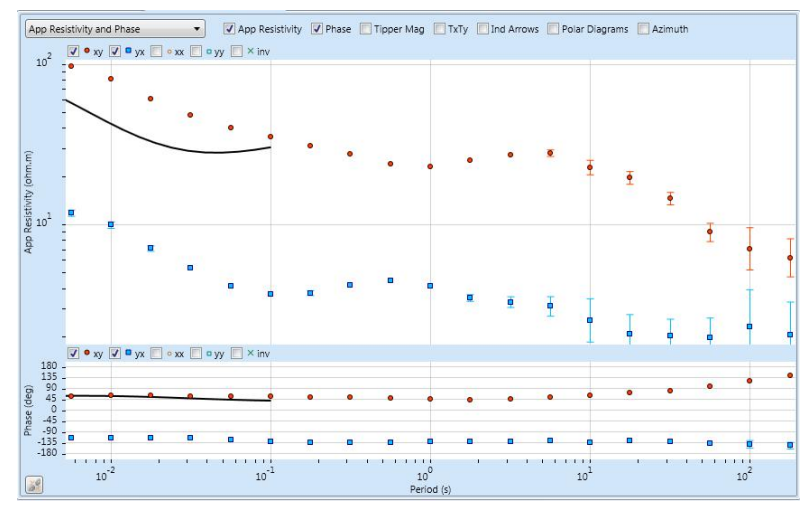

(a)

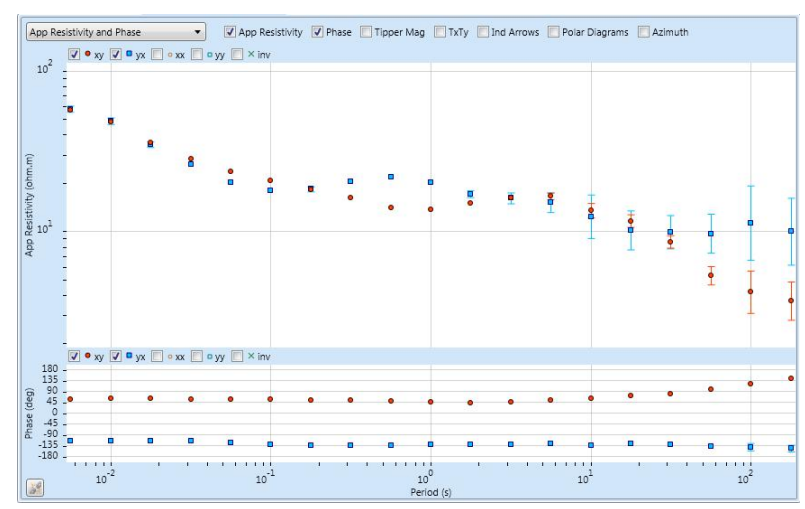

(b)

Fig. 2: (a) Sounding curve before static shift correction with TDEM data (b) Sounding curve resulting from static shift correction with TDEM data

The sounding curves in Fig. 2 and Fig. 3 after static shift correction were good enough because the electric transverse (TE) and magnetic transverse (TM) curves on most data were quite coincided, which meant that the effect of the static effect was not so great. The curve in Fig. 2 showed a high apparent resistivity at the initial frequency and increasingly showed a low apparent resistivity to the final frequency. This indicated that at shallow depths there were rocks with high resistivity, but as the depth increased the resistivity value of rocks was identified to be low. While on the curve of Fig. 3 shows the apparent resistivity value that fluctuated. Starting from the moderate apparent resistivity value and continuous fluctuation until the final. 


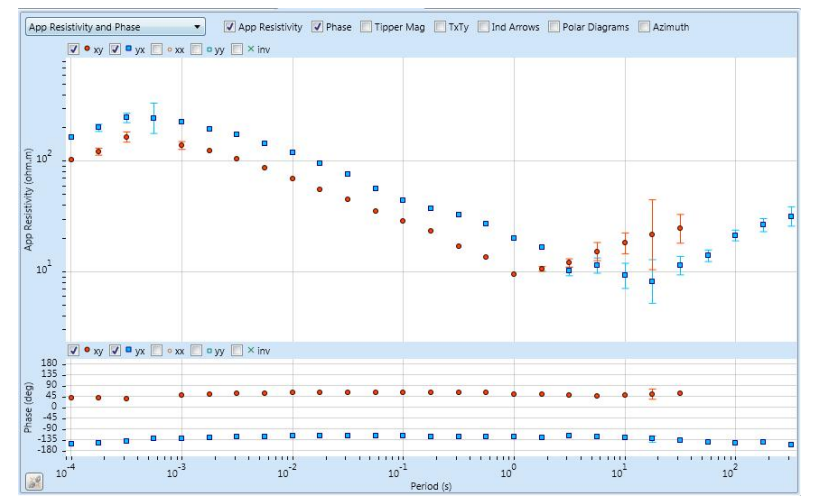

(a)

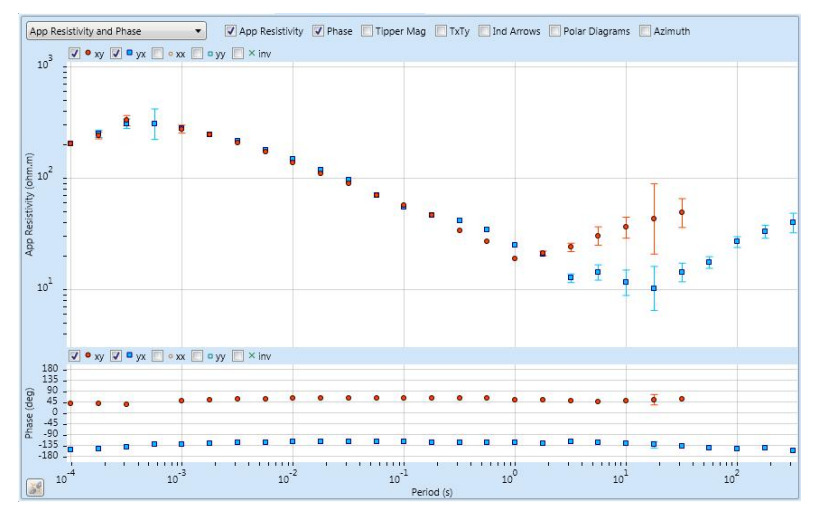

(b)

Fig. 3: (a) Sounding curve before static shift correction (b) Sounding curve after static shift correction with spatial filtering method

frequency value of apparent resistivity was moderate. This indicated that at shallow depths there were rocks with resistivity values that were not too high and then deeper rocks were identified with moderate resistivity values up to the deepest depths there were rocks with high resistivity.

2D inversion modeling was done by cutting line in the Northwest - Southeast and Southwest Northeast directions to get a lateral and vertical view of resistivity throughout the "N" Geothermal Field. The mode used in modeling was the TE-TM mode to get a better model in describing horizontal and vertical resistivity variations.

In the modeling of the Northwest - Southeast there were 3 lines, namely A, B, and C, all of which were identical. This line intersected the manifestations in the form of fumaroles on NMB and $\mathrm{NKH}$. The manifestation of NMB and NKH lied at the intersection of lane $B$ shown in Fig. 4. Line B consisted of 24 stations and ran along the NW-SE. Line B crossed two manifestations, namely NMB and $\mathrm{NKH}$ with a maximum limit of resistivity value of 400 $\Omega \mathrm{m}$ and a maximum depth of $3000 \mathrm{~m}$ below sea level. The results of 2D inversion of line B are shown in Fig. 5.

Contour maps with resistivity values of $10 \Omega . m$ from inversion modeling were used to map the Base of conductive layer or the lowest point of the conductive zone while the resistivity values between $10 \Omega . m-60 \Omega . m$ were used to map reservoir layers. [12].

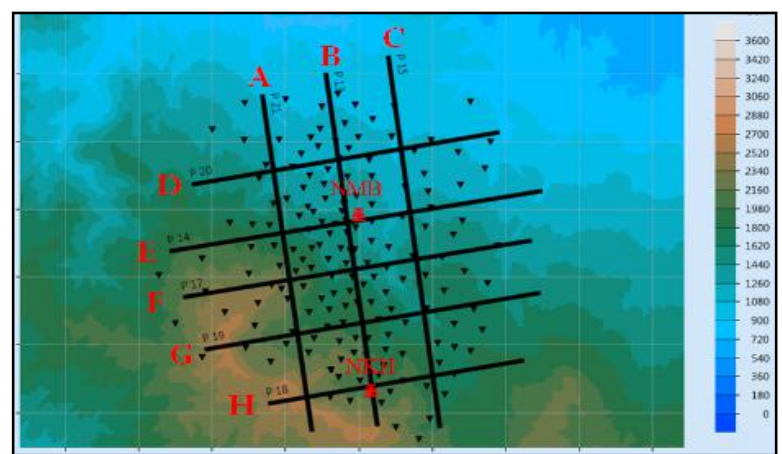

Fig. 4: Line profile in the study area

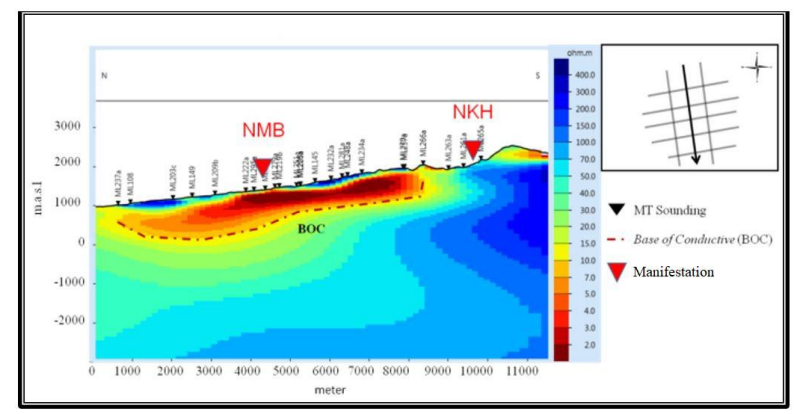

Fig. 5: 2D model of line B

The location of the low resistivity layer was identified in line B with a resistivity value of $2 \Omega$.m $10 \Omega$.m was found in shallow depths of 2000 meters above sea level to 0 meters above sea level. At this line, it was also identified medium resistivity layer (11 $\Omega . m$ - $70 \Omega . m$ ) which was located below the conductive zone boundary which was increasingly thickened towards the north. Under the medium resistivity layer, there was a layer with high resistivity (more than $71 \Omega . \mathrm{m}$ ) which led to the south side. In this line, there were two manifestations in the form of fumaroles at the point of NMB and NKH. The low resistivity layer was thought to be a cap rock layer covering about 1,000 m thick, the medium resistivity layer was thought to be a layer containing a reservoir.

In the Southwest - Northeast there were 5 Lines namely $\mathrm{D}, \mathrm{E}, \mathrm{F}, \mathrm{G}$, and $\mathrm{H}$ which could be seen in Fig. 4. This line was tangent to the northwest-southeast line. The line in this direction was intended to see the resistivity that intersected the three initial line and to see the southernmost side of the "N" Geothermal Field. These lines passed through the manifestations of $\mathrm{NMB}$ and $\mathrm{NKH}$ respectively through line $\mathrm{E}$ and $\mathrm{H}$. Line $\mathrm{E}$ consisted of 14 stations and ran along the SW-NE. this line crossed the manifestation of NMB with a maximum limit of resistivity value of $400 \Omega \mathrm{m}$ and a maximum depth of 2000 meters below sea level. The results of 2D inversion of line E are shown in Fig. 6.

The conductive zone on line E was interpreted with a resistivity value of $2 \Omega . m$ - $10 \Omega . m$ and was located at a depth of 2000 to 0 meters above sea level. The thickness of the cap rock zone on Line $\mathrm{E}$ was around 1000 meters. The medium resistivity zone (11 $\Omega . \mathrm{m}-70 \Omega . \mathrm{m})$ was shown by yellow to light blue which was thought to be a reservoir layer that was increasingly spreading eastward from the line. There were also layers with high resistivity, with resistivity values of more than $70 \Omega$.m. 


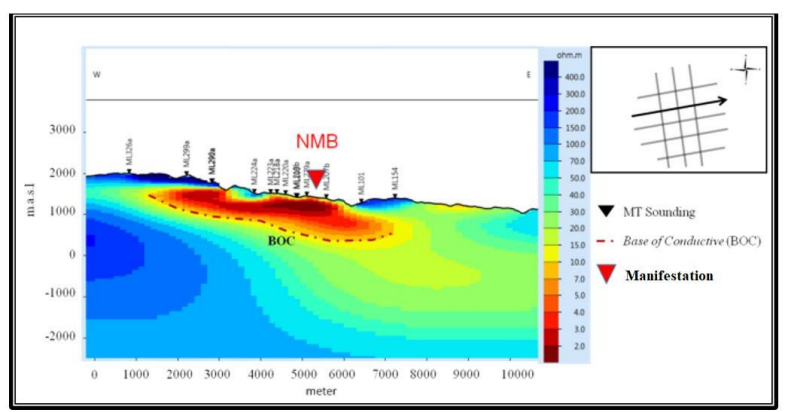

Fig. 6: 2D model of line $\mathrm{E}$

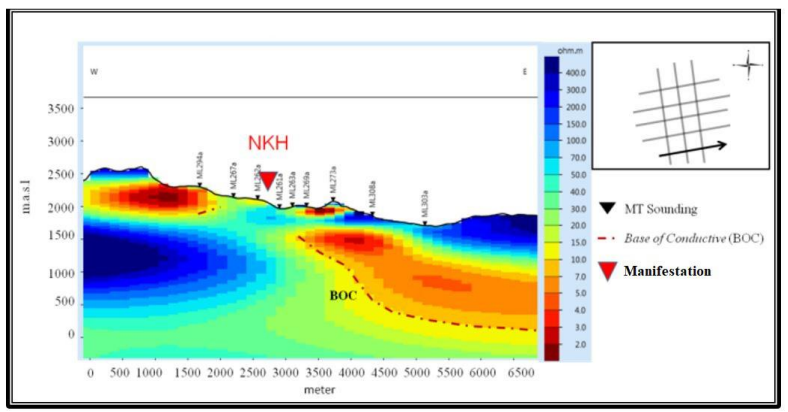

Fig. 7: 2D model of line $H$

Line $\mathrm{H}$ consisted of 9 stations in the SW-NE direction. Line $\mathrm{H}$ crossed the manifestations of $\mathrm{NKH}$ with a maximum limit of resistivity value of $400 \Omega \mathrm{m}$ and a maximum depth of $0 \mathrm{~m}$ above sea level. The results of 2D inversion of line $\mathrm{H}$ are shown in Fig. 7.

Low resistivity zones ( $2 \Omega . m-10 \Omega . m)$ on line $H$ were on two sides, which were located on the west and east sides which were bounded by a medium resistivity layer (11 $\Omega \mathrm{m}-70 \Omega \mathrm{m}$ ). This layer was thought to be cap rock. On the west side, the thickness of the conductive zone was approximately 500 meters. However, in the western part of the line, there was a lack of data that could make the data incorrect. On the east side, the thickness of the conductive zone was approximately 1000 meters. The deepest point of the conductive zone was located at a depth of 0 meters above sea level, while the shallower point of the conductive zone was located at a depth of 2000 meters above sea level. Just below the conductive zone, there was a layer with a moderate resistivity value which was thought to be a reservoir layer. There was also a layer of high resistivity which was located at a depth of approximately 1500 meters above sea level on the west side of the track called the resistive zone.This line intersected the manifestation in the form of fumarole at the NKH manifestation.

The location of the low resistivity layer in this study was almost the same as the conceptual model created by [13] in their research, as shown in Fig. 8. In conceptual model, it was found that the depth of the low resistivity layer lies at a depth of $2000 \mathrm{~m}$ to $0 \mathrm{~m}$ above sea level, and has a thickness of approximately $1000 \mathrm{~m}$.

Based on the results of 2D inversion modeling in this research, it was known that the resistivity range in the "N" Geothermal Field was in the range of $2 \Omega . \mathrm{m}$ to $400 \Omega . \mathrm{m}$. There was a very significant color difference between layers with low resistivity values and layers that had moderate to high resistivity values. The low resistivity layer (cap rock) was interpreted with a resistivity value of $2 \Omega . \mathrm{m}-10$ $\Omega$.mand was located at a depth of $2000 \mathrm{~m}$ to $0 \mathrm{~m}$ above sea level. The moderate resistivity layer was being interpreted with a resistivity value of $11 \Omega . \mathrm{m}$ $70 \Omega . m$ and the high resistivity layer was interpreted with a greater resistivity value from 70 S.m.

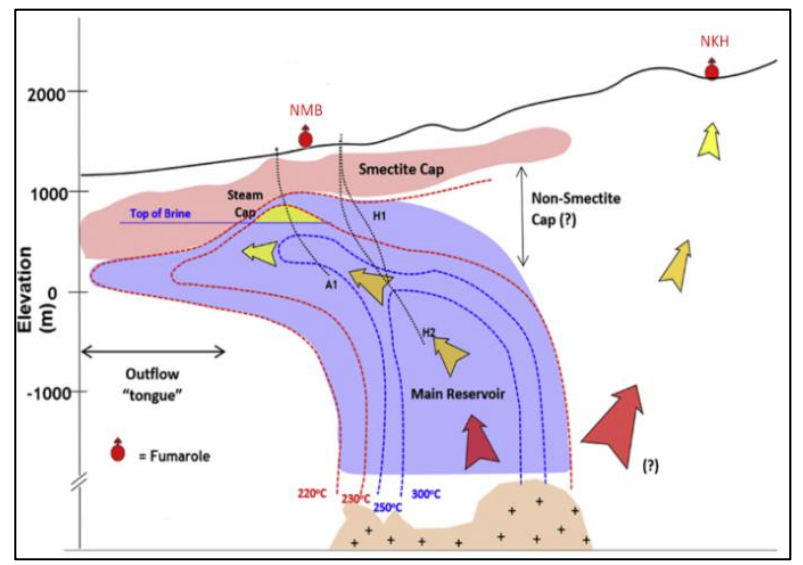

Fig. 8: Conceptual model [13]

The low resistivity layer was interpreted as a cap rock due to the high clay mineral content in the rock, the low value of cap rock resistivity was caused by the response of the altered rock due to the interaction between the hot fluid and the surrounding rock [14]. Layers with moderate resistivity were usually thought of as rocks that function as reservoirs. This layer had a higher resistivity value compared to cap rock because the number of clay minerals presented in the constituent rocks had been reduced.

\section{Conclusions}

The two-dimensional resistivity model in the " $\mathrm{N}$ " geothermal field identifies layers with a range of resistivity values of $2 \Omega . m$ to $400 \Omega$.m. The layer with low resistivity ( $2 \Omega . m-10 \Omega . m$ ) is thought to be a layer containing hydrothermally altered rocks interpreted as a cap rock layer. A layer with a medium resistivity value (11 $\Omega . m-70 \Omega . m)$ is interpreted as a zone that contains a reservoir in the "N" geothermal field. Layers with resistivity values of more than $70 \Omega . m$ are interpreted as resistive zones. The escalation in resistivity value is caused by the reduction in clay minerals in rocks. The location of the low resistivity layer (cap rock) on the geothermal field "N" is located at a shallow depth close to the surface. The depth of the cap rock lies in the range of $2000 \mathrm{~m}$ above sea level to reach the lowest point at a depth of approximately $0 \mathrm{~m}$ above sea level with an average thickness of approximately $1000 \mathrm{~m}$.

\section{Acknowledgment}

The research was supported by PT Supreme Energy, Jakarta, Indonesia.

\section{References}

1. G. Ussher, C. Harver, R. Johnstone, and E. Anderson, "Understanding the Resistivities Observed in Geothermal Systems," World Geotherm. Congress, Kyushu-Tohoku, Japan (2000) 
2. L. Zhang, T. Hao, Q. Xiao, J. Wang, L. Zhou, M. Qi, and N. Cai, "Magnetotelluric investigation of the geothermal anomaly in Hailin, Mudanjiang, northeastern China," J. App. Geophys. 118 47-65 (2015)

3. F. Simpson, and K. Bahr, Practical Magnetotelluric, Cambridge University Press, United Kingdom (2005)

4. G. D. Naidu, "Deep Crustal Structure of the SonNarmada-Tapti Lineament, Central India,"

Dissertation, Department of Geophysics, Osmania University, Hyderabad (2014)

5. P. M. Wright, S. H. Ward, H. P. Ross, and R. West, "State of the art geophysical exploration for geothermal resources," Geophys. 50 2666-2696 (1985)

6. E. Anderson, D. Crosby, and G. Ussher, "Bull's Eye! - Simple resistivity imaging to reliably locate the geothermal reservoir," Proceedings World Geotherm. Congress 2000 909-914 (2000)

7. D. A. Dyaksa, I. Ramadhan, and N. Ganefianto, "Magnetotelluric reliability for exploration drilling stage: study cases in Muara Laboh and Rantau Dedap geothermal project, Sumatera, Indonesia," Proceedings $41^{\text {st }}$ Workshop on Geotherm. Reservoir Engineering (2016)

8. A. Aragón-Aguilar, G. Izquierdo-Montalvo, S. López-Blanco, and V. Arellano-Gómez, "Analysis of heterogeneous characteristics in a geothermal area with low permeability and high temperature," Geosci. Frontiers 85 1039-1050 (2017)
9. U. K. Borah, P. K. Patro, and V. Suresh, "Processing of noisy magnetotelluric time-series from Koyna-Warna seismic region, India: a systematic approach", CSIR-National Geophysical Research Institute, Hyderabad, India, Annals of Geophys. 58 (2015)

10. H. M. D. Rosidi, S. Tjokrosapoetro, B. Pendowo, S. Gafoer, and Suharsono, "Peta Geologi Lembar Painan dan Bagian Timurlaut Lembar Muarasiberut, Sumatera," Pusat Penelitian dan Pengembangan Geologi, Bandung (1996)

11. A. L. Hendro, and H. Grandis, "Koreksi efek statik pada data magnetotellurik menggunakan data elektromagnetik transien," Proceedings Himpunan Ahli Geofisika Indonesia, Jakarta (1996)

12. L. Pellerin, J. M. Johnston, and G. W. Hohmann, "A numerical evaluation of electromagnetic methods in geothermal exploration," Geophys. 61 121-130 (1996)

13. J. Stimac, N. Ganefianto, M. Baroek, M. Sihotang, I. Ramadhan, W. Mussofan, R. Sidik, Alfiady, D. A. Dyaksa, H. Azis, A. P. Putra, R. Martikno, R. Irsahamukti, S. Santana, K. Matsuda, H. Hatanaka, Y. Soeda, L. Carlou, and P. Egermann, "An overview of the Muara Laboh geothermal system, Sumatra", Geothermics 82 150-167 (2019)

14. S. Maryanto, C. N. Dewi, V. Syahra, A. Rachmansyah, J. H. Foster, A. Nadhir, and D. R. Santoso, "Magnetotelluric-geochemistry investigations of Blawan geothermal field, East Java, Indonesia," Geosci. 7 (2017) 